\title{
A ABORDAGEM SISTÊMICA E 0 CICLO DE VIDA DO LICOR DE MACAÚBA
}

\section{THE SYSTEMIC APPROACH AND THE LIFE CYCLE OF MACAUBA LIQUOR}

\author{
ADRIANA LUISA DUARTE | UEMG \\ ALICE NOVATO SILVA DE FARIA | UEMG \\ LUDMILA C. F. MENDES | UEMG \\ KÁTIA ANDRÉA CARVALHAES PÊGO, Dra.| UEMG \\ ANDRÉA FRANCO PEREIRA, Dra. | UEMG
}

\begin{abstract}
RESUMO
O modelo mecanicista, baseado no pensamento linear, vem produzindo uma realidade insustentável, doentia e desumana. Torna-se urgente a reavaliação das cadeias de produção, à luz do pensamento sistêmico. Necessários são a compreensão dos processos envolvidos nos sistemas produtivos e o entendimento das inter-relações existentes nos mesmos. Assim, o método de Avaliação do Ciclo de Vida se apresenta como técnica eficaz para avaliar os impactos ambientais provocados pelo sistema. Igualmente, o contexto do território no qual o mesmo está inserido deve ser considerado. Diante disto, este estudo buscou analisar a produção do licor de macaúba no território do Serro (MG). O extrativismo da macaúba (Acrocomia aculeata), palmeira perene da região, é praticado no território, apresentando potencial para criação, sob a perspectiva do Design Sistêmico, de atividades interconectadas e a implantação de um macrossistema. A análise do Inventário de Ciclo de Vida permitiu observar impacto potencial, relativo ao aquecimento global, ligado à emissão de CO2 devida aos transportes - embora possa haver sequestro de parte dessas emissões, pelas próprias palmeiras. Os pontos problemáticos observados podem ser, no entanto, considerados como 'alavancas para mudanças', permitindo a identificação de novas atividades produtivas, gerando trabalho e renda para a comunidade.
\end{abstract}

PALAVRAS-CHAVE: Inventário do Ciclo de Vida; Pensamento Sistêmico; Licor de Macaúba; Aquecimento global.

\begin{abstract}
The mechanistic model, based on linear thinking, has been producing an unsustainable, unhealthy and inhuman reality. The reassessment of production chains, in the light of systemic thinking, is urgent. Necessary are the understanding of the processes involved in the productive systems and the understanding of the interrelationships existing in them. Thus, the Life Cycle Assessment method presents itself as an effective technique to assess the environmental impacts caused by the system. Likewise, the context of the territory in which it is inserted must be considered. Therefore, this study sought to analyze the production of macaúba liquor in the territory of Serro (MG). The extractivism of macaúba (Acrocomia aculeata), a perennial palm tree in the region, is practiced in the territory, presenting potential for the creation, from the perspective of Systemic Design, of interconnected activities and the implementation of a macro-system. The analysis of the Life Cycle Inventory made it possible to observe a potential impact, related to global warming, linked to the emission of $\mathrm{CO} 2$ due to transport - although part of these emissions may be sequestered by the palm trees themselves. The problematic points observed can, however, be considered as 'levers for change', allowing the identifcation of new productive activities, generating work and income for the community.
\end{abstract}

KEY WORDS: Life Cycle Inventory; Systemic Thinking; Macauba Liquor; Global warming. 


\section{INTRODUÇÃO}

Ao analisar a história da ciência, Kuhn (2018) critica a visão de processo cumulativo de conhecimento e alega que sua evolução se configura como uma sucessão de períodos de "ciência normal", suspensa por "revoluções científicas", derivando, então, em novas maneiras de perceber o mundo. Estas "mudanças de paradigmas" ocorrem em períodos excepcionais e revolucionários, nos quais o "velho paradigma" é substituído por um novo. Tal dinâmica é de ordem radical, de fundamento, impondo a redefinição do problema a ser estudado e a forma de sua resolução.

Segundo o autor, na evolução da ciência, é possível perceber uma alternância entre duas linhas de pensamento distintas: (i) o pensamento racionalista, também denominado linear ou mecanicista, cujo método racional dedutivo, proposto por René Descartes (1569 - 1650), consiste em decompor um fenômeno em partes para entender o comportamento do todo, a partir das propriedades e comportamento de suas partes; (ii) o pensamento holístico, ou sistêmico, no qual um fenômeno não é mais observado a partir da análise de suas partes separadamente, mas a partir da compreensão do todo, caracterizando, portanto, uma "mudança de paradigma". Nesta perspectiva, entende-se que o mundo é formado por sistemas complexos interligados - cujas partes estão em constante interação -, e nos quais o ambiente influencia e é influenciado. Sendo assim, ao invés de se restringir a visão em busca da identificação das partes elementares, deve-se buscar contextualizar o fenômeno a ser investigado, identificando o "todo" que contém as "partes" e suas inter-relações.

Sendo assim, um pensamento holístico, que estivera presente na idade antiga e na renascença, fora reintroduzido na contemporaneidade com o desenvolvimento de novas teorias científicas, tais como a Teoria Geral dos Sistemas de Ludwig von Bertalanffy (1901 - 1972) e o Paradigma da Complexidade de Edgar Morin (1921 - até o presente), tendo sido estas fundamentais para o fortalecimento do pensamento ambientalista, especialmente, a partir da década de 1970.

Atualmente, como se sabe, a sociedade enfrenta a maior e mais grave crise ambiental de origem antropogênica. Segundo Capra (1987), todas as crises contemporâneas são facetas de uma única: a "crise de percepção". Esta resulta do fato de que, ainda hoje, se busca aplicar conceitos de uma visão arcaica de mundo - sob o espectro mecanicista da ciência cartesiana-newtoniana -, a uma realidade que já não pode mais ser compreendida por esta ótica. De acordo com o autor, ciência e tecnologia estão baseadas na crença seiscentista de que a compreensão da natureza implica em sua dominação pelo ser humano. Este modelo mecanicista de observação do universo, com destaque excessivo dado ao pensamento linear, produziu uma tecnologia doentia e desumana. Seus objetivos envolvem, basicamente, o controle, a produção em massa e a padronização.

O secretário-geral das Nações Unidas, António Guterres (2021), enviou uma mensagem para o Dia Mundial do Meio Ambiente (em 05 de junho de 2021), na qual declara que atualmente "Enfrentamos uma tripla emergência ambiental - perda de biodiversidade, disrupção climática e poluição crescente. [...] Estamos devastando os mesmos ecossistemas que sustentam as nossas sociedades. E, ao fazê-lo, corremos o risco de nos privar de alimentos, de água e dos recursos necessários para sobreviver". Contudo, acrescenta que "Ainda temos tempo de reverter os estragos que temos causado". Foi por este motivo que a ONU lançou a "Década das Nações Unidas da Restauração de Ecossistemas". De acordo com Guterres, "Ao restaurarmos os ecossistemas, poderemos conduzir uma transformação que irá contribuir para alcançar os Objetivos de Desenvolvimento Sustentável".

Tal chamamento, certamente, ecoa no campo do design, pois salienta a pertinência e a urgência da reavaliação (visando restauração) dos modelos de produção e consumo vigentes, à luz do pensamento sistêmico.

Nessa complexa e ampla conjuntura, ressalta-se a quantidade exorbitante de Resíduos Sólidos Urbanos (RSU) produzidos no Brasil. Em 2010, foram gerados 67 milhões de toneladas de RSU no País. Em 2019, este montante teve aumento de 18\%, totalizando 79 milhões t/ano. A fração orgânica (45,3\%), principal componente dos RSU, permaneceu a mesma nesse período (ABRELPE, 2020). Tal realidade se apresenta como um reflexo da aplicação do clássico modelo linear de desenvolvimento: extração > produção > uso > disposição.

Diante disto, o estudo aprofundado das inter-relações existentes nas etapas das cadeias produtivas se faz urgente. A compreensão dos processos envolvidos - nos quais os insumos sofrem transformações -, aliada ao entendimento sobre as características das matérias-primas empregadas, permite vislumbrar soluções, com vistas a minimizar os impactos ambientais negativos, advindos de todo o ciclo de vida de um determinado artefato. Para tanto, o método de Avaliação do Ciclo de Vida (ACV) se apresenta como uma técnica eficaz, que permite avaliar os aspectos ambientais e os impactos potenciais associados a um produto, "[...] compreendendo etapas que vão desde a retirada da natureza das matérias-primas elementares que entram no sistema produtivo (berço) à disposição do produto final (túmulo)" (CHEHEBE, 1997). 
Importante destacar que, além da cadeia produtiva propriamente dita de um determinado artefato, o contexto no qual a mesma está inserida deve ser considerado, uma vez que o território e suas características ambientais, econômicas, sociais, e culturais, também afetam e são afetados pelos processos de fabricação.

Sendo assim, este artigo busca compreender os aspectos ambientais associados aos processos produtivos de um determinado produto, de maneira mais ampla, observando o contexto sistêmico de seu território. Busca, igualmente, evidenciar a identificação de novas oportunidades, a partir da compreensão do todo, além de auxiliar o projetista nas tomadas de decisão.

Para tanto, a produção do licor de macaúba, produzido artesanalmente por uma comunidade de mulheres do distrito de São Gonçalo do Rio das Pedras, localizado na Região do Serro (MG), foi utilizada como objeto de investigação.

O estudo apresentado a seguir foi, originalmente, publicado no IX Encontro de Sustentabilidade em Projeto (DUARTE et al., 2021) e, aqui revisado, detalha o Inventário de Ciclo de Vida (ICV), uma das etapas do método de ACV, do sistema de produção do licor de macaúba, mencionado acima.

\section{CONTEXTUALIZAÇÃO}

A espécie Acrocomia aculeata, popularmente conhecida como macaúba, é uma palmeira oleaginosa originária da América tropical e abundantemente encontrada em quatro ecossistemas brasileiros: Cerrado, Mata Atlântica, Floresta Amazônica e Pantanal. Com longa história de exploração extrativista no País, o valor econômico desta palmeira está associado à sua elevada capacidade produtiva e à ampla possibilidade de aproveitamento de seu fruto. No Brasil, maciços naturais de macaúba ocorrem desde o Pará até o Estado do Paraná, principalmente, nas áreas de Cerrado e em ambientes de floresta sub-caducifólia.

Atualmente, esses maciços são mais expressivos nos Estados de Goiás, Minas Gerais, Mato Grosso e Mato Grosso do Sul, onde predominam condições climáticas características do bioma Cerrado (LORENZI, 2006, p. 62).

A macaúba é uma das espécies mais promissoras para produção de biodiesel na atualidade, principalmente, em razão da excelente qualidade intrínseca do óleo da polpa da fruta (NUNES et al., 2015) e do bom rendimento bruto de óleo por prensagem do fruto fresco, que pode atingir 4 t/ha/ano (EMBRAPA, 2014).

O plantio racional dessa cultura teve início em 2009, com desenvolvimento de tecnologia para a quebra da dormência de suas sementes pela Universidade Federal de Viçosa, o que possibilitou a produção de mudas em grande escala, considerada, até então, o gargalo para o desenvolvimento de plantios organizados dessa palmeira (MOTOIKE et al., 2010).

Pertencente à família Arecaceae, a macaúba é uma palmeira perene, com 10 a $15 \mathrm{~m}$ de altura e 20 a $30 \mathrm{~cm}$ de diâmetro na fase adulta. A região dos nós é coberta de espinhos escuros, pontiagudos com cerca de $10 \mathrm{~cm}$ de comprimento (MOTA et al., 2011). As palmeiras possuem folhagem plumosa com folhas entre 1,5 a $3 \mathrm{~m}$ de comprimento. Produzem anualmente entre 4 e 8 cachos de frutos com cerca de 150 a 350 frutos por cacho, variando entre $2,5 \mathrm{~cm}$ e $5,0 \mathrm{~cm}$ de diâmetro e pesando de $15 \mathrm{~g}$ a 50 $g$ por fruto (SILVA, 1994).

A macaúba apresenta elevada produtividade a partir do sétimo ano de crescimento, com vida útil de exploração superior a 25 anos. Atualmente, no território do Serro (MG), sua exploração é extrativista, aproveitando os povoamentos nativos da planta. Um estudo de balanço de massas dos frutos da macaúba (FAVARO et al. 2018, p. 22) "apresentou valores médios ao longo do armazenamento de $19 \%$ de casca, $40 \%$ de polpa e $39 \%$ de endocarpo, juntamente com a amêndoa". A Figura 1 representa a composição do fruto.

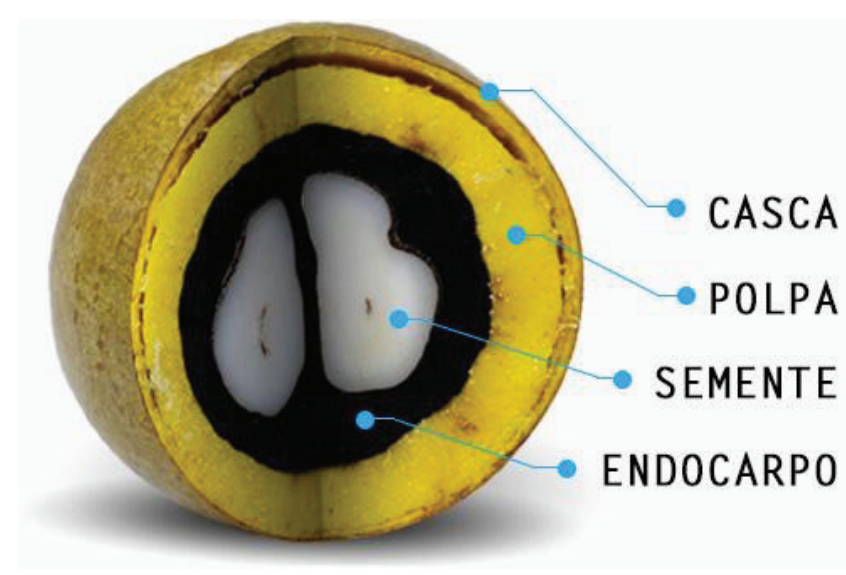

Figura 01 - Estrutura do fruto de macaúba Fonte: QUEIROGA (2016)

O objeto de estudo nesta análise é o licor de macaúba. O território em questão, denominado Território do Serro, se encontra na Estrada Real (MG). O município do Serro está localizado a cerca de $330 \mathrm{~km}$ de distância da capital de Minas Gerais, Belo Horizonte, ocupa uma área de $1.217,813 \mathrm{~km}^{2}$ e registra uma densidade demográfica de 17,11 hab/ $\mathrm{km}^{2}$ (IBGE, 2010). De acordo com o último CENSO, realizado em 2010, sua população é de 20.835 habitantes, sendo que $62 \%$ desta vivem na área urbana e $38 \%$ na área rural (IBGE, 2010). 
Sede de uma das quatro primeiras comarcas da Capitania das Minas Gerais, a antiga Vila do Príncipe do Serro Frio, atualmente, cidade do Serro (Figura 2), ainda guarda as características das vilas setecentistas mineiras, o que lhe valeu ser o primeiro município brasileiro a ter seu conjunto arquitetônico e urbanístico tombado pelo Instituto do Patrimônio Histórico e Artístico Nacional (IPHAN) em abril de 1938.

A região é banhada pelas bacias hidrográficas dos rios Doce, Jequitinhonha e São Francisco. O sistema de abastecimento de água e de esgotamento sanitário é realizado no município do Serro, assim como no restante do Estado, pela Companhia de Saneamento do Estado de Minas Gerais (COPASA). A rede geral de abastecimento de água atende a $64,40 \%$ dos domicílios, enquanto $29,27 \%$ são providos por poço ou nascentes particulares e 6,33\% possuem forma diversa de abastecimento de água (IBGE, 2000). Muitos povoados da região, assim como outros em todo o Brasil, que ainda não têm acesso ao sistema de abastecimento de água, são atendidos pelo Programa Água para Todos, implantado, em 2011, pelo Governo Federal. A energia elétrica é fornecida pela Companhia Energética de Minas Gerais (CEMIG), responsável por $96 \%$ do abastecimento.

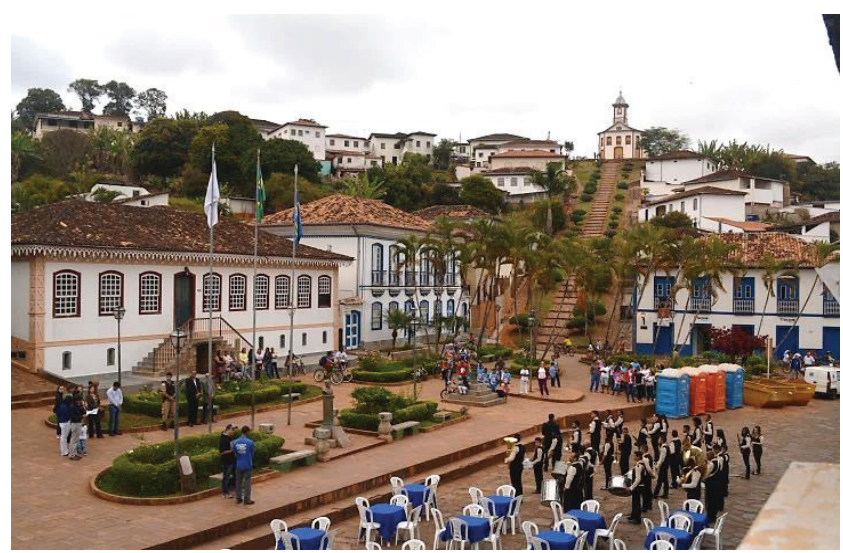

Figura 02 - Cidade do Serro

Fonte: PREFEITURA DO MUNICÍPIO DO SERRO (2019)

Segundo a Empresa de Assistência Técnica e Extensão Rural do Estado de Minas Gerais (EMATER-MG), o município possui "cerca de $11 \%$ de área plana, 22\% de área ondulada e 67\% de área montanhosa" (EMATER-MG, [200-?], p. 9). Sua altitude varia entre 600 e 1.200 m, com vegetação de Cerrado, dos tipos: campo limpo, campo sujo, cerradão, mata ciliar, vereda e cerrado típico. Segundo Andrade et al. (2017), o Cerrado é o segundo maior bioma do Brasil, ocupando $24 \%$ do território nacional e aproximadamente $50 \%$ de Minas Gerais.
Dentre as árvores nativas presentes na Região do Serro, encontra-se a macaúba que, como dito, é explorada de forma extrativista há várias gerações pela população local, que se organiza em grupos de produtores ou cooperativas para otimizar o aproveitamento da colheita.

A palmeira de macaúba se destaca por sua rusticidade e produtividade. Além dos óleos produzidos a partir da polpa e da amêndoa, o processamento do fruto da macaúba gera coprodutos de grande valor agregado, que vão desde produtos alimentícios a farmacêuticos e cosméticos, como também a produção de peças artesanais. Além disto, a torta da amêndoa, resíduo obtido a partir da prensagem desta para extração de óleo, é muito valorizada como ingrediente para compor a ração animal, visto ser rica em proteína. Já a torta da polpa pode ser utilizada como combustível de caldeira, por seu alto poder calorífico $(4.706 \mathrm{Kcal} / \mathrm{kg}$ ), como ingrediente para ração de ruminantes e como fertilizante, pois é muito rica em potássio, sódio, cálcio e fósforo. Apesar de as tortas da casca e da polpa serem pobres em proteína, ambas são muito ricas em fibras, sendo indicadas para fertilização do solo, bem como insumo calorífico nas caldeiras e fundições (SILVA et al., 2008).

A seguir, serão descritos os materiais e métodos empregados na elaboração do Inventário do Ciclo de Vida da produção de licor de macaúba, no território do Serro (MG).

\section{MATERIAIS E MÉTODOS}

Como tratado anteriormente, a Avaliação do Ciclo de Vida (ACV) é um método que possibilita quantificar os impactos ambientais provocados por um produto, auxiliando os projetistas em suas tomadas de decisão. A aplicação da ACV permite a análise de todo o ciclo de vida do produto, desde a extração dos recursos naturais, passando pelos processos de transformação e produção dessa matéria-prima, até o uso e a disposição final dos artefatos e dos e materiais (COLTRO, 2007; PEREIRA; OLIVEIRA, 2014).

De acordo com Coltro (2007), as discussões sobre a extração de recursos naturais, desencadeadas pela crise do petróleo, levaram ao início dos estudos sobre ACV, na década de 1960. Segundo a autora, tais estudos enfraqueceram após a crise do petróleo e ressurgiram, na década de 1980, devido ao aumento do interesse por pesquisas sobre o meio ambiente. Porém, somente na década de 1990 a ideia de ciclo de vida foi formalizada, por meio das Normas da série ISO 14000. Assim, a série ISO 14040 descreve o método e os princípios para efetivação de uma ACV (PEREIRA; OLIVEIRA, 2014).

As fases elementares de um estudo de ACV incluem, primeiramente, a definição dos Objetos e do Escopo, nos quais são estabelecidos o campo e as fronteiras do estudo, bem 
como a Unidade Funcional (UF), ou seja, a referência quantitativa do fluxo de entrada e saída de materiais, energia e resíduos no sistema analisado. Em seguida, é realizada a Análise do Inventário, momento em que são levantados todos os processos envolvidos e quantificadas as entradas e saídas para todas as etapas do ciclo de vida do sistema. A elaboração de um modelo de representação, por meio de um fluxograma, facilita a visualização dos processos incluídos no inventário e o registro dos dados quantitativos levantados. A terceira fase diz respeito à Avaliação do Impacto, possível por meio do cálculo do balanço do fluxo de entrada e saída, a partir dos dados obtidos na fase anterior. Esse cálculo resulta em indicadores numéricos, gerados em unidades de medidas, que permitem a análise de diferentes categorias de impacto, tais como, por exemplo, a categoria de impacto "aquecimento global" medida em Dióxido de Carbono (CO2) equivalente. Por fim, a última fase trata da Interpretação do ciclo de vida, na qual é compreendido e analisado o impacto provocado pelo sistema, levando-se em conta as fases anteriores, bem como outros critérios ligados às incertezas, à integridade e à sensibilidade do estudo (COLTRO, 2007; PEREIRA, 2017).

De acordo com Pereira (2017), a etapa de elaboração do inventário é essencial para a aplicação de uma ACV. A autora afirma que o inventário dos fluxos de matéria, energia e resíduo, deve considerar: (i) os critérios para a aquisição de dados; (ii) a qualidade dos dados de entrada; (iii) o uso de dados atualizados; (iv) a definição das entradas e saídas de recursos; (v) as categorias de dados. Coltro (2007) destaca, ainda, a importância da qualidade dos dados utilizados, para maximizar a confiabilidade dos resultados e, por conseguinte, das conclusões.

Baseado na metodologia de ACV e de acordo com a norma ISO 14040, neste estudo, foram considerados os seguintes parâmetros:

- A função do sistema tecnológico é a produção do licor de polpa de macaúba;

- A UF (unidade funcional) do sistema é de 500 litros de licor;

- Por se tratar de uma atividade realizada de maneira extrativista e em sistema de cooperativa, os limites do sistema incluem o crescimento de frutos até a destinação para consumo final;

- A cobertura geográfica do sistema é parcial, onde os principais processos foram modelados conforme informações disponibilizadas pela Embrapa (PENHA, 2006) acerca da produção de frutos, bem como da produção de licor de frutas;

- Os valores estimados para emissões de CO2 foram obtidos por meio da calculadora virtual do Laboratório de Silvicultura Tropical (LASTROP, 2021) da Universidade de São Paulo;
- A cobertura temporal abrange a base de dados da Embrapa (PENHA, 2006), para os processos de produção do licor, além de dados primários sobre a região, coletados na tese de Pêgo (2016);

- A cobertura tecnológica também é parcial, e os principais processos representam tecnologias específicas do sistema em avaliação;

- Os dados de entrada relevantes foram coletados, em sua maioria, por meio de fontes secundárias, considerando que a cadeia produtiva está em construção. Os dados de saída foram calculados com base nos insumos, por meio da aplicação de equações e modelos relacionados ao tema, disponíveis na literatura técnica e científica. Nenhum critério de corte foi estabelecido.

\section{RESULTADOS}

Na fase agrícola, foram considerados os seguintes processos: crescimento das palmeiras, coleta e seleção de frutos. Na fase agroindustrial, foram considerados os processos: despolpamento, maceração, trasfega, adição de açúcar, filtragem e envase. Na fase de varejo, foram considerados: varejo e consumo.

O fluxograma com todos os processos identificados está representado na Figura 3.

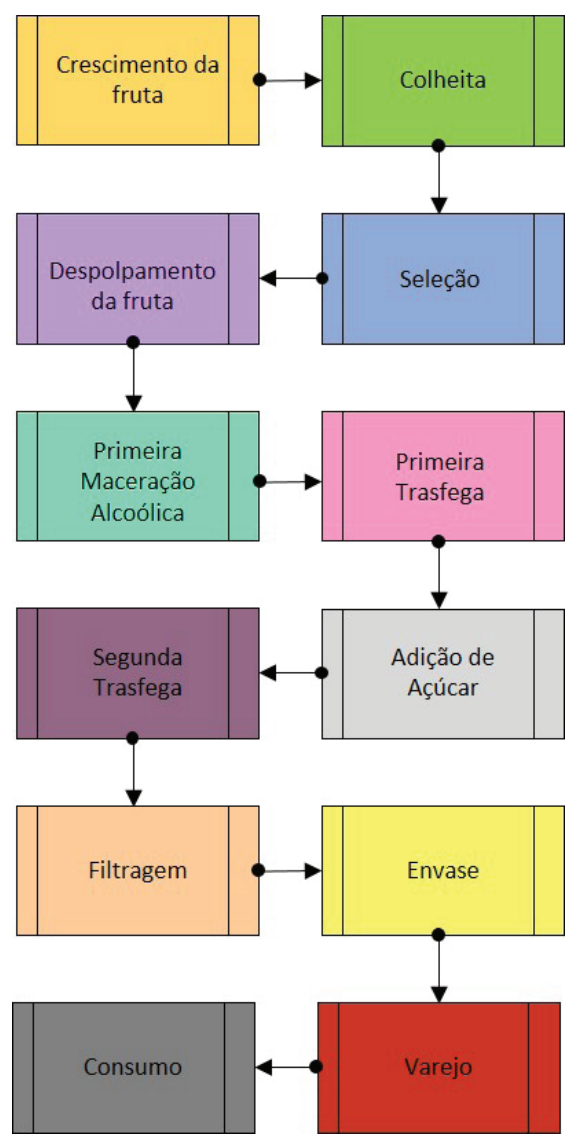

Figura 03 - Processos considerados no ICV Licor de macaúba Fonte: Elaborado pelas AUTORAS 


\subsection{Do extrativismo à seleção dos frutos}

Em relação ao uso da terra, considerou-se que se trata de área agrícola com mais de 20 anos de uso, como mencionado anteriormente e, como o manejo da macaúba ocorre de maneira extrativista, não foram incluídas neste estudo as etapas de plantio e preparação da terra. A macaúba inicia o seu período de frutificação a partir do sétimo ano de vida e estima-se que a árvore seja produtiva por um período de, no mínimo, 30 anos.

Normalmente, a manutenção da cultura de macaúba consiste, basicamente, na aplicação de fertilizantes e controle de plantas daninhas. Neste modelo, considerou-se somente o controle de ervas daninhas, que é realizado manualmente em torno das palmeiras, e capina mecânica sobre as parcelas. Considerou-se, também, a etapa de irrigação, realizada por sistema de gotejamento.

A macaúba floresce entre os meses de setembro e novembro e o período de maturação dos frutos varia de 12 a 14 meses após o florescimento. No estudo em questão, considerou-se que cada árvore produz cinco cachos, com cerca de 250 frutos por cacho, e que cada fruto pesa $30 \mathrm{~g}$, resultando em $37.500 \mathrm{~kg}$ de fruta por árvore, anualmente. A Figura 4 ilustra o primeiro processo do ciclo, que corresponde ao crescimento da fruta.

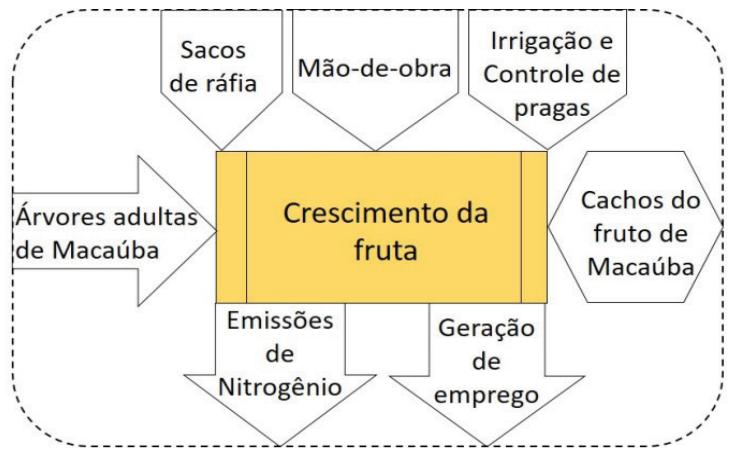

Figura 04 - ICV Licor de macaúba - Crescimento da fruta Fonte: Elaborado pelas AUTORAS

As emissões de nitrogênio foram consideradas, com base nos fatores de emissão indicados por Malavolta e Moraes (2006). Como resultado, para cada quilograma de nitrogênio aplicado, considerou-se a emissão de $0,08 \mathrm{~kg}$ de $\mathrm{N} 2,0,013 \mathrm{~kg}$ de N2O, 0,16 kg de NH3, 0,03 kg de $\mathrm{NO}$ e $0,05 \mathrm{~kg}$ de NO3.

De acordo com Penha (2006), após a maturação, os frutos se desprendem naturalmente dos cachos e são recolhidos, tradicionalmente, de maneira manual em explorações extrativistas. Para tanto, os colhedores precisam vistoriar todas as palmeiras uma vez ao dia. Ocorre também a coIheita manual dos cachos com o uso de foice, quando se retira todo o cacho de frutos de uma só vez. Os frutos são armazenados em cestos de palha que são reutilizados nas próximas colheitas. Na etapa de colheita (Figura 5), são eliminados os sabugos do cacho, galhos e frutos podres, que são destinados à compostagem ou aterro sanitário.

Os frutos coletados são acondicionados em recipientes do tipo tonéis de boca larga, cobertos por telas protetoras, e armazenados em galpão. Os frutos podem permanecer nessas condições por, no máximo, sete dias antes da higienização.

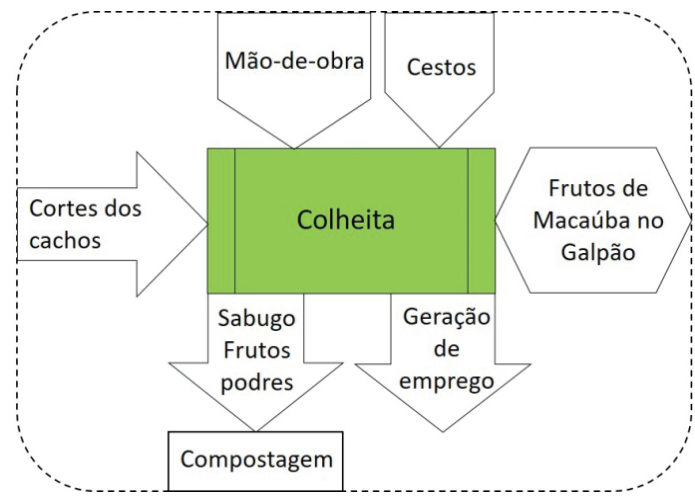

Figura 05 - ICV Licor de macaúba - Colheita

Fonte: Elaborado pelas AUTORAS

Para a higienização, os frutos são, inicialmente, lavados com água corrente, a fim de eliminar resíduos de terra e demais materiais orgânicos. Em seguida, os frutos são colocados em um tanque com água e solução clorada, onde permanecem por cerca de 10 minutos para desinfecção. Nesta etapa, os frutos danificados boiam e acontece, assim, a primeira seleção. Os colhedores são responsáveis por toda a etapa de higienização, bem como pelo processo de seleção, realizada manualmente (Figura 6). Segundo os colhedores mais antigos e experientes, os frutos de boa qualidade são aqueles cujo "olho" ainda tem a coloração alaranjada; os mais amarronzados já estão com a polpa seca e perderam a qualidade.

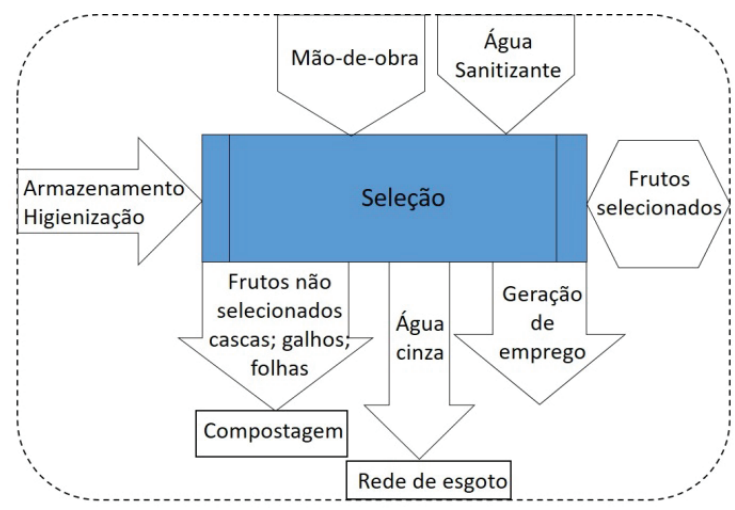

Figura 06 - ICV Licor de macaúba - Seleção Fonte: Elaborado pelas AUTORAS 
Nessa etapa de seleção, os frutos rachados, danificados, quebrados, verdes, maduros demais e podres, assim como galhos, folhas e casca são separados e, posteriormente, destinados à compostagem. Sendo assim, somente aqueles furtos selecionados, caracterizados pela boa qualidade, seguem para as etapas de processamento e industrialização. A água resultante da higienização é despejada na rede de esgotamento público.

\subsection{Fabricação do licor}

Para a realização do cálculo do número de frutos necessários para a produção da UF de 500 litros de licor de macaúba, foi necessário considerar algumas padronizações referentes ao peso e à composição do fruto. Baseado em Queiroga (2016), Sanjinez-Argandoña e Chuba (2011), definiu-se que a polpa de macaúba representa $40 \%$ do peso total do fruto que, como média, recebeu um peso igual a $30 \mathrm{~g}$. Assim, para a produção de 500 litros do licor, seriam necessários 37.840 frutos provenientes de 31 palmeiras de macaúba, totalizando 1.135,2 kg de macaúba.

Neste processo do ciclo de vida do licor de macaúba (Figura 7), os frutos já selecionados, higienizados e secos, passam por uma despolpadora mecânica pneumática, que consome 0,35 kWh por um período de, aproximadamente, 19 horas, para a realização da separação do fruto entre casca, semente e polpa.

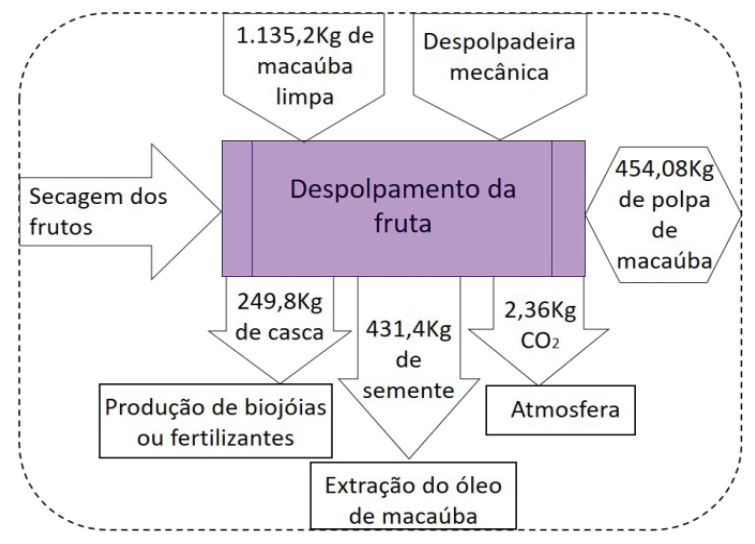

Figura 07 - ICV Licor de macaúba - Despolpamento da fruta Fonte: Elaborado pelas AUTORAS

Como resultado desse processo, são obtidos: (i) 249,9 kg de casca, que pode ser destinada para a produção de biojoias; (ii) 431,4 kg de semente, destinada para a extração de óleo; (iii) liberação de 2,36 kg de $\mathrm{CO} 2$, referente ao consumo energético necessário; (iv) 454,08 kg de polpa de macaúba.

Seguindo a proporção de uma parte de polpa para uma parte de álcool de cereais apresentada por Penha (2006), aos 454,08 kg de polpa de macaúba são acrescidos 454,08
L de álcool de cereais, estes provenientes da cidade de Belo Horizonte, distante $220 \mathrm{~km}$ da cidade do Serro (MG). Ao final desse processo (Figura 8), são liberados 225,21 kg de $\mathrm{CO} 2$, decorrente do transporte do álcool, por meio de um caminhão leve, e obtidos 454,08 L de Infusão Alcoólica.

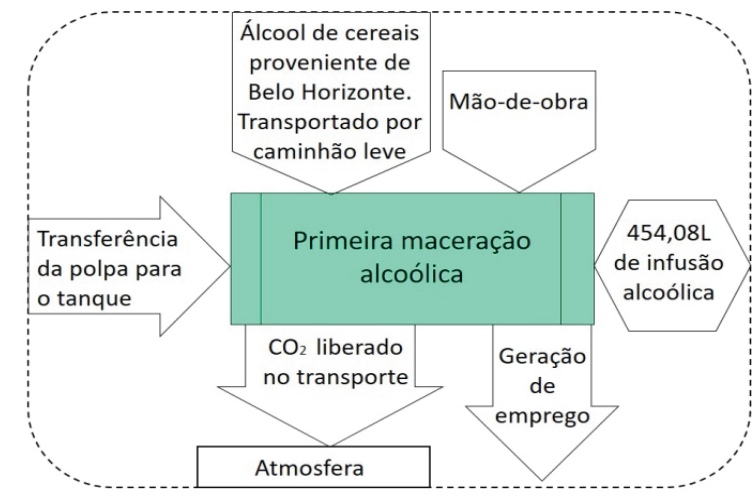

Figura 08 - ICV Licor de macaúba - Primeira maceração Fonte: Elaborado pelas AUTORAS

Posteriormente, essa infusão passa por um período de repouso de 15 dias, no qual ocorre a decantação dos resíduos sólidos. Na sequência, essa solução é transferida para um tanque com sifão, onde ocorre a drenagem da solução alcoólica e a retirada dos resíduos sólidos (1a borra). Este processo, denominado Primeira Trasfega, é representado na Figura 9.

Baseado em processo similar de fabricação de vinho branco, apresentado por Rizzon e Dall'Agnol (2009), considerou-se que a $1^{\text {a }}$ borra obtida na Primeira Trasfega corresponde a $10 \%$ do volume total da infusão antes desta etapa, ou seja, 41,281 L de solução. Sendo assim, o resultado da primeira trasfega equivale a $412,8 \mathrm{~L}$ do chamado "licor primário" que é transferido para outro tanque sem sifão.

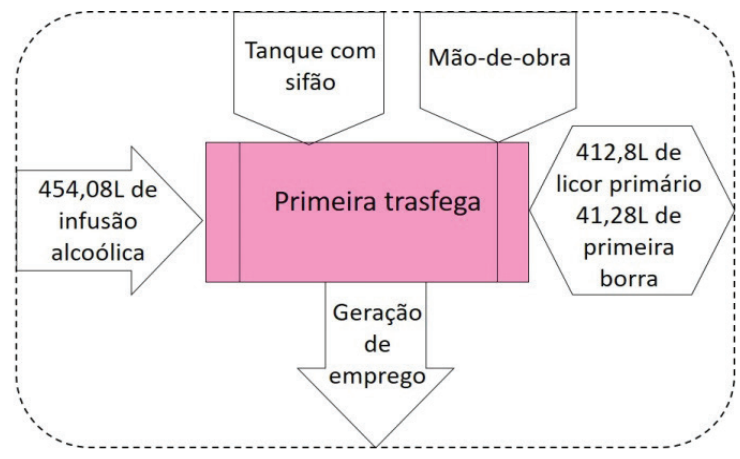

Figura 09-ICV Licor de macaúba - Primeira trasfega Fonte: Elaborado pelas AUTORAS

O próximo processo, ilustrado na Figura 10, é a adição do açúcar ao licor primário, por meio do preparo de um xarope de açúcar com a proporção de duas partes de 
água para uma parte de açúcar (PENHA, 2006). Para a produção de 500 L de xarope de açúcar, são necessários 103,7 $\mathrm{kg}$ de açúcar. Esse açúcar é também proveniente de Belo Horizonte, a $220 \mathrm{~km}$ do Serro (MG) e transportado por um caminhão leve, liberando $225,21 \mathrm{~kg}$ de $\mathrm{CO} 2$ para a atmosfera, além do descarte das embalagens dos insumos, que são destinadas a aterros sanitários.

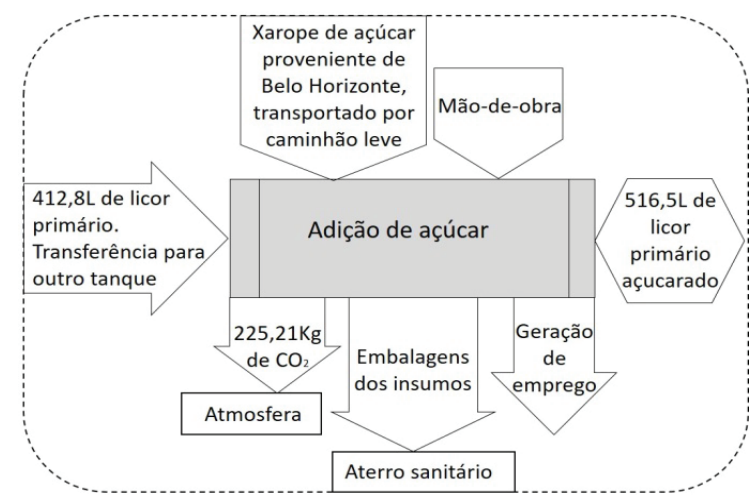

Figura 10 - ICV Licor de macaúba - Adição de açúcar Fonte: Elaborado pelas AUTORAS

O penúltimo processo de fabricação do licor se refere à Segunda Trasfega (Figura 11).

Assim como na Primeira Trasfega, os 516,5 L de licor primário, agora açucarados, são mantidos em repouso por um período de 15 dias antes de serem transferidos para um tanque com sifão. Para esse processo, definiu-se que $5 \%$ da quantidade de licor primário açucarado comporia a denominada $2^{\mathrm{a}}$ borra $(25,8 \mathrm{~L})$, sendo os $490,6 \mathrm{~L}$ restantes transformados em licor secundário.

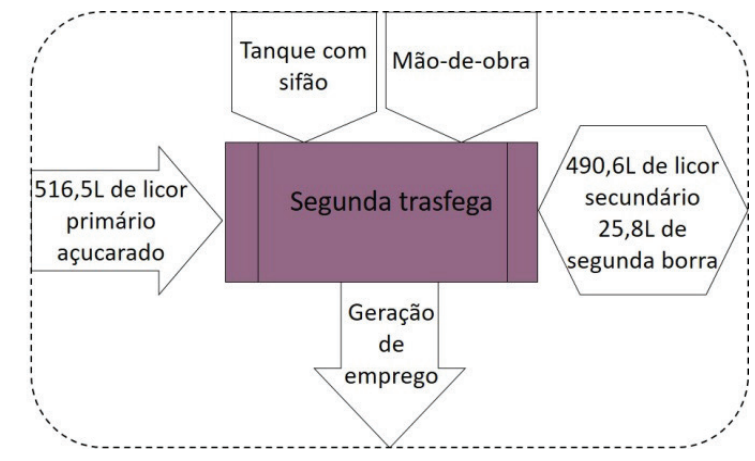

Figura 11 - ICV Licor de macaúba - Segunda trasfega Fonte: Elaborado pelas AUTORAS

Por fim, o licor secundário é submetido ao processo de filtragem, com filtros reutilizáveis após sua higienização. Paralelamente, tanto a $1^{\text {a }}$ quanto a $2^{\text {a }}$ borra $(67,08 \mathrm{~L}$ no total) também são submetidas ao processo de filtragem para evitar o desperdício de licor, que poderia ser descartado em conjunto com as demais saídas. $\mathrm{O}$ resultado desse processo corresponte à UF definida anteriormente de $500 \mathrm{~L}$ de licor de macaúba, que são transferidos para outra área da planta de fabricação para seu envase. Além disso, considerou-se que nem todo o licor seria possível de ser utilizado. Assim, uma das saídas desse processo inclui 57,7 L de borra ou de licor com impurezas, conforme representado na Figura 12.

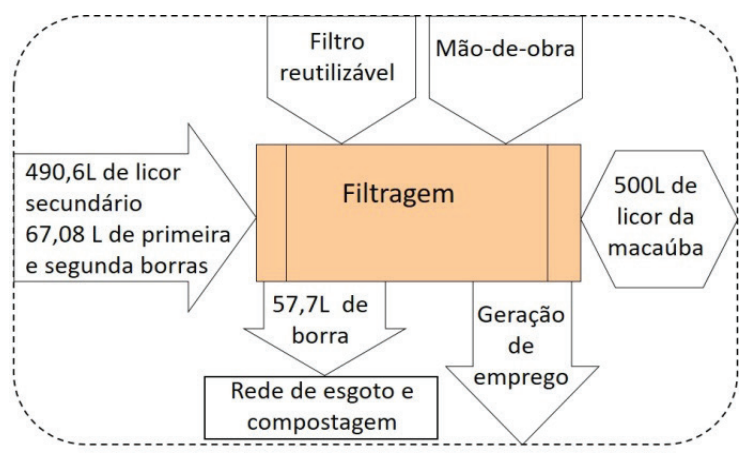

Figura 12 - ICV Licor de macaúba - Filtragem Fonte: Elaborado pelas AUTORAS

Para o processo de envase, foram identificadas como entradas as embalagens de vidro necessárias para acondicionar o licor, bem como os rótulos de identificação da bebida e as rolhas para permitir seu fechamento. Para tanto, foi necessário estabelecer um quantitativo de embalagens, rolhas e rótulos, baseado na UF definida. Dessa forma, foi adotado o uso de 500 garrafas de vidro com rolha, com capacidade para um litro, e 500 rótulos de papel.

Diante disto, foi preciso identificar o local de procedência destas embalagens e rótulos. Em pesquisa realizada na mesma região, sobre a produção de cosméticos, Pêgo (2016) indicou que as embalagens destes produtos eram oriundas de Belo Horizonte, distante $220 \mathrm{~km}$ do Serro (MG), e que os rótulos eram provenientes de Diamantina (MG), distante $22 \mathrm{~km}$ do Serro (MG). Sendo assim, as distâncias destas cidades até o local de produção do licor foram consideradas para o cálculo de combustível necessário para o transporte dos respectivos materiais para o envase. Para as garrafas, foi estimado o consumo de $73 \mathrm{~L}$ de diesel, para o transporte por meio de um caminhão leve. Já para os rótulos, foi considerado o consumo de 1,75 L de gasolina, para um veículo de passeio.

Além dos materiais para a embalagem, no processo de envase foi identificada, como entrada, a energia elétrica necessária para o funcionamento de uma máquina envasadora eletropneumática. Como se trata de uma produção artesanal, optou-se pelo uso de um equipamento simples e portátil (Figura 13), com potência de 10 W, cujo tempo de operação para o envase de todas as garrafas 
seria de 20 minutos, resultando em um consumo de 3,33 kWh. A mão de obra para a operação da máquina também foi considerada uma entrada.

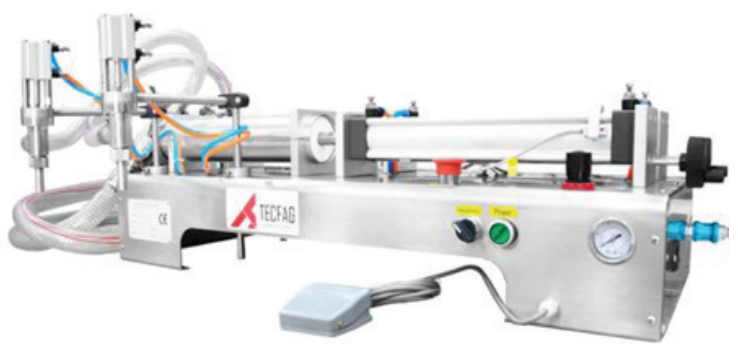

Figura 13 - Exemplo de máquina envasadora portátil de mesa Fonte: TECFAG (2021)

Importante ressaltar que, antes do envase, as garrafas devem passar por um processo de higienização, que consiste na imersão em solução clorada e posterior imersão em água fervente (PENHA, 2006). Sendo assim, o sistema apresentou como saída os resíduos dos produtos químicos utilizados na limpeza das embalagens. Ainda neste processo, o sistema emite um total de $267,81 \mathrm{~kg}$ de $\mathrm{CO} 2$ liberados para a atmosfera, em decorrência do transporte das embalagens e do consumo de energia para o envase. Deste valor, o transporte equivale a $99,7 \%$ do total de CO2 liberado. O resultado corresponde a 500 garrafas rotuladas de licor de macaúba, como ilustrado na Figura 14.

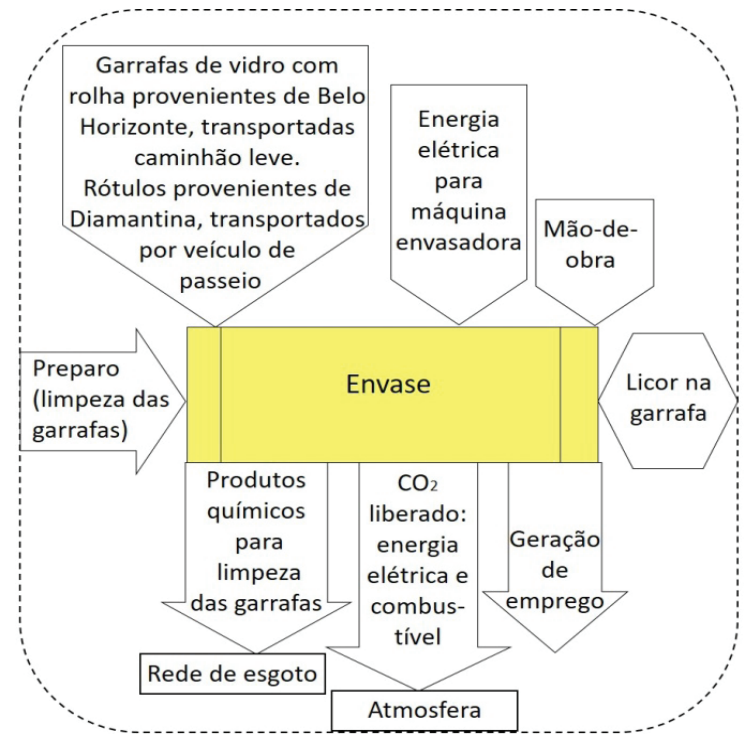

Figura 14 - ICV Licor de macaúba - Envase Fonte: Elaborado pelas AUTORAS

Por fim, foi estabelecido que as 500 garrafas de licor de macaúba seriam transportadas do distrito de São Gonçalo do Rio das Pedras para o Serro (MG), distante 31 $\mathrm{km}$, para serem comercializadas.

\subsection{Varejo e consumo}

Para o processo correspondente ao varejo (Figura 15), foram observadas como entradas do sistema a energia elétrica, necessária para o funcionamento do estabelecimento que irá comercializar o licor, além da mão de obra, necessária para a realização de sua venda. Este processo apresenta como saída o CO2 estimado em 31,73 kg, liberado pelo transporte do licor, por meio de caminhão leve, do local de produção até o varejo.

A taxa de $\mathrm{CO} 2$ liberada pelo consumo de energia elétrica do estabelecimento também deve ser considerada uma saída do sistema. Contudo, devido às variáveis relacionadas a esta emissão, tal valor não foi quantificado. Ressalta-se, ainda, que este processo apresenta como saída positiva a geração de emprego e renda, decorrente da comercialização dos licores.

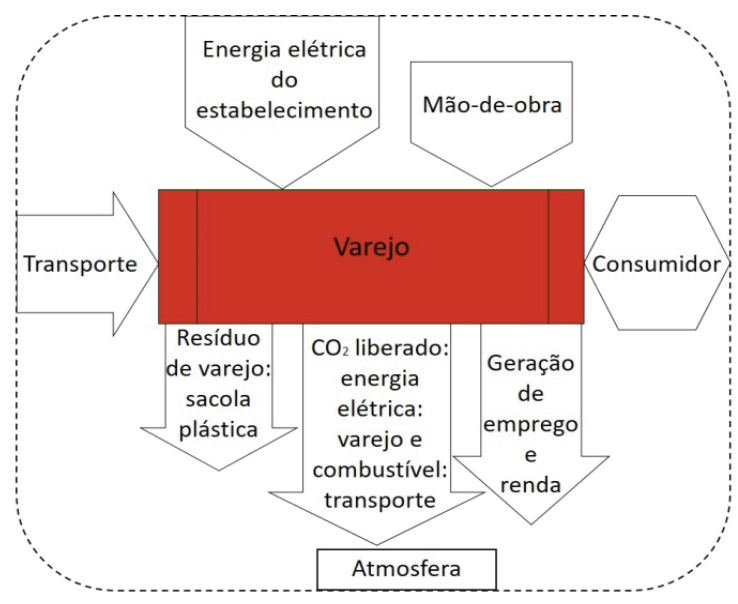

Figura 15 - ICV Licor de macaúba - Varejo Fonte: Elaborado pelas AUTORAS

Finalmente, no processo de consumo do licor, foram identificadas as seguintes saídas: garrafa de vidro, rolhas e rótulos (Figura 16).

Destaca-se que o transporte do licor, do varejo até o local de consumo, é uma fase de transição, que pode apresentar, como saída, maior ou menor quantidade de emissão de $\mathrm{CO} 2$, dependendo das distâncias percorridas e dos meios de transporte empregados.

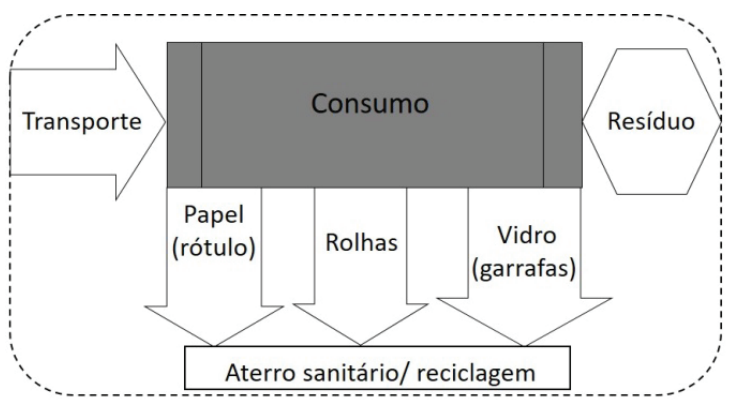

Figura 16 - ICV Licor de macaúba - Consumo Fonte: Elaborado pelas AUTORAS 
Por fim, cabe ressaltar que o sistema de produção de licor aqui estudado não deve ser considerado isoladamente, mas sim como um subsistema integrado à totalidade do território. Assim, em uma perspectiva de sustentabilidade, as saídas observadas neste subsistema devem se transformar em entradas para outros processos, preferencialmente no mesmo território, permitindo a criação de atividades interconectadas e a formação de um macrossistema que, na perspectiva do Design Sistêmico, como defende Bistagnino (2011), se caracteriza pela interconexão e interdependência de diversos subsistemas.

\section{CONSIDERAÇÕES FINAIS}

A transição de um modelo econômico linear - caracterizado por uma dinâmica que consiste na extração, produção, distribuição, consumo e descarte - para um modelo circular, no qual as saídas de um sistema se configurem como entradas para outro sistema, não se reduz a ajustes com vistas à diminuição dos impactos negativos. Tal transição se configura como uma mudança sistêmica, que se edifica em longo-prazo.

Entretanto, a compreensão dos processos envolvidos e a análise quantitativa dos impactos gerados permitem que sejam vislumbradas soluções, não somente para a minimização de tais impactos observados, mas, também, para a consideração dos fatores ambientais, econômicos, sociais, e culturais do território no qual o sistema está inserido, integrando tais aspectos que afetam e são afetados pelos processos de fabricação.

Nesse sentido, a ACV se apresenta como uma importante ferramenta no âmbito do desenvolvimento de sistemas produtivos, principalmente, em razão do detaIhamento dos processos envolvidos no ciclo de vida do produto e da identificação de pontos problemáticos, tais como: (i) desperdício de matéria e energia durante os processos; (ii) consumo excessivo de insumos externos ao território - não locais; (iii) emprego de componentes/substâncias nocivos aos trabalhadores e/ou ao meio ambiente; (iv) uso de substâncias poluentes.

Neste estudo, a partir dos dados analisados, foi possível observar impacto potencial relativo ao aquecimento global. O sistema de produção de licor de macaúba libera em torno de $712,32 \mathrm{~kg}$ de $\mathrm{CO} 2$ para a atmosfera, principalmente, devidos ao transporte necessário para a obtenção de insumos externos ao território, como também ao transporte utilizado na distribuição do produto final.

Não obstante, cabe ressaltar que, possivelmente, parte desse impacto possa ser compensada pelo sequestro de CO2 promovido pelas próprias palmeiras de macaúba, tendo em vista o caráter de perenidade das árvores, favorecido pela atividade extrativista.

Importante destacar, também, que este estudo foi realizado de maneira teórica, não sendo possível uma visita técnica presencial ao território analisado, devido às restrições impostas pela pandemia do Sars-CoV-2. Desta maneira, as quantidades e medidas, apresentadas neste artigo, foram obtidas com base em outras pesquisas relacionadas ao processo estudado. Assim, alterações em relação aos valores reais são possíveis, tendo em vista que fatores diversos podem contribuir para essas diferenças, tais como a variação do peso dos frutos, a temperatura do local de produção do licor etc.

Os pontos problemáticos observados aqui podem ser, no entanto, considerados como 'alavancas para mudanças'. Nessa perspectiva, as oportunidades são exploradas com o intuito de idealizar novas atividades produtivas, que possam emergir do sistema e, consequentemente, gerar trabaIho e renda para as pessoas no próprio território.

Da mesma maneira, as saídas resultantes do consumo final do produto (garrafas de vidro, rolhas e rótulos) devem, preferencialmente, ser consideradas como entrada em outros sistemas produtivos - como indica a metodologia do Design Sistêmico.

Certamente, esta mudança de paradigma não é uma tarefa trivial. Entretanto, acredita-se que os profissionais do design, dadas as características intrínsecas de sua atividade, tais como visão multifacetada, multidisciplinariedade, trânsito entre as diversas camadas e setores da sociedade, sejam capazes de assumir uma fração de responsabilidade na reavaliação das atividades produtivas, visando à restauração tanto dos ecossistemas naturais quanto dos sistemas antrópicos produzidos pelas necessidades humanas.

\section{AGRADECIMENTOS}

Agradecimentos ao Conselho Nacional de Desenvolvimento Científico e Tecnológico (CNPq), à Fundação de Amparo à Pesquisa do Estado de Minas Gerais (FAPEMIG), à Coordenação de Aperfeiçoamento de Pessoal de Nível Superior (CAPES), à Universidade do Estado de Minas Gerais e à Universidade Federal de Minas Gerais, que permitiram a realização desta pesquisa.

\section{REFERÊNCIAS}

ABRELPE. Panorama dos resíduos sólidos no Brasil 2020. São Paulo: ABRELPE, 2020. 52 p. Disponível em: https://abrelpe.org.br/panorama/. Acesso em: 05 jun. 2021.

ANDRADE, R. G. et al. Avaliação das condições de 
pastagens no cerrado brasileiro por meio de geotecnologias. Revista Brasileira de Agropecuária Sustentável (RBAS), v.7, n.1, p.34-41, Março, 2017. CAPRA, F. The turning point: science, society, and the rising culture. New York: Bantam Books, 1987.

BISTAGNINO, L. Design sistemico: progettare la sostenibilità produttiva e ambientale. Bra: Slow Food, 2011.

CHEHEBE, J. R. Análise do ciclo de vida de produtos: ferramenta gerencial da ISO 14000. Rio de Janeiro: Qualitymark, 1997.

COLTRO, L. Avaliação do ciclo de vida - ACV. In: COLTRO, L. (org). Avaliação do ciclo de vida como instrumento de gestão. Campinas: CETEA/ITAL, 2007. DUARTE, A. L. et al. Inventário de Ciclo de Vida para uma Produção artesanal de Licor de Macaúba no território do Serro / Minas Gerais. Anais do ENSUS 2021

- IX Encontro de Sustentabilidade em Projeto 2021, Florianópolis, 2021.

EMPRESA BRASILEIRA DE PESQUISA AGROPECUÁRIA (EMPRAPA). Macaúba é matéria-prima promissora para biodiesel. 2014. Disponível em: https://www. embrapa.br/busca-de-noticias/-/noticia/2329636/macauba-e-materia-prima-promissora-para-biodiesel. Acesso em: 14 fev. 2021.

EMPRESA DE ASSISTÊNCIA TÉCNICA E EXTENSÃO RURAL DO ESTADO DE MINAS GERAIS (EMATER-MG) Caracterização da Região do Serro como Produtora de Queijo Minas Artesanal. Belo Horizonte: EMATER, [200-?]. Disponível em: https://www.emater.mg.gov. br/doc/intranet/upload/QUEIJO_HISTORICO/DOSSIÊ DO SERRO def2.pdf. Acesso em: 24 maio 2021.

FAVARO, S. et al. Armazenamento e processamento da macaúba: contribuições para manutenção da qualidade e aumento do rendimento de óleo da polpa. Brasília: EMBRAPA Agroenergia, 2018. Disponível em: https://ainfo.cnptia.embrapa.br/digital/bitstream/ item/186831/1/BPD-16-CNPAE.pdf. Acesso em: 13 jan. 2021.

GUTERRES, A. Dia Mundial do Meio Ambiente 2021: mensagem do secretário-geral da ONU Disponível em: https://brasil.un.org/pt-br/130019-dia-mundial-do-meio-ambiente-2021-mensagem-do-secretario-geral-da-onu. Acesso em: 05 jun. 2021.

INSTITUTO BRASILEIRO DE GEOGRAFIA E ESTATÍSTICA (IBGE). IBGE Cidades. Rio de Janeiro: IBGE, 2000. Disponível em: http://www.ibge.gov.br. Acesso em: 02 fev. 2014.

INSTITUTO BRASILEIRO DE GEOGRAFIA E ESTATÍSTICA
(IBGE). Serro - Censo Demográfico 2010. Disponível em: https://censo2010.ibge.gov.br/sinopse/index. php?dados=29\&uf=31. Acesso em: 19 fev. 2021.

KUHN, T. S. A estrutura das revoluções científicas. São Paulo: Perspectiva, 2018.

LASTROP - Laboratório de Silvicultura Tropical. 2021. Disponível em: http://esalqlastrop.com.br/capa.asp?pi=calculadora_emissoes\#: :text $=1 \% 20$ litro $\% 20$ de\%20gasolina\%20\%3D\%201,kg\%20CO2\%20emitido\%20por\%20litro. Acesso em: jan. 2021.

LORENZI, G. M. A. C. Acrocomia aculeata (Jacq.) Lodd. ex Mart. - Arecaceae: bases para o extrativismo sustentável. 2006. 172 f. Tese (Doutorado em agronomia) Curso de Pós-graduação em Agronomia, Universidade Federal do Paraná, Curitiba, 2006. Disponível em: https://acervodigital.ufpr.br/handle/1884/5279. Acesso em 29 maio 2021.

MALAVOLTA, E.; MORAES, M. F. O nitrogênio na agricultura brasileira. Série de Estudos e DocumentosSED-70. Brasília: CETEM/MCT, 2006.

MOTA, C. S. et al. Exploração sustentável da macaúba para produção de biodiesel: colheita, pós-colheita e qualidade dos frutos. Informe Agropecuário, Belo Horizonte, v. 32, n. 265, p. 41-51, 2011 Disponível em https://www.researchgate.net/publication/264520394_Exploracao_sustentavel_da_macauba_para_producao_de_biodiesel_Colheita_pos-colheita_e_qualidade_dos_frutos. Acesso em: 28 maio 2021.

MOTOIKE, S. Y. et al. Produção de mudas de macaúba. Boletim Técnico. Viçosa: Acrotech, 2010.

NUNES, A. A.; FAVARO, S. P.; GALVANI, F.; MIRANDA, C. $H$. B. Good practices of harvest and processing provide high quality Macauba pulp oil. European Journal of Lipid Science and Technology, v. 117, n. 12, p. 20362043, 2015. Disponível em: https://onlinelibrary.wiley. com/doi/abs/10.1002/ejlt.201400577. Acesso em: 06 maio 2021.

PÊGO, K. A. C. Approach of the systemic design in material and intangible culture of Estrada Real: territorial Serro case. Turin: Politecnico di Torino, 2016. Disponível em: https://iris.polito.it/retrieve/handle/11583/2644209/116354/Tesi Carvalhaes Pêgo.pdf. Acesso em: 2 fev. 2021.

PENHA, E. das M. Licor de Frutas. Brasília: Embrapa Informação Tecnológica, 2006. Disponível em: https:// www.embrapa.br/busca-de-publicacoes/-/publicacao/416490/licor-de-frutas. Acesso em: 13 jan. 2021. PEREIRA, A. F.; OLIVEIRA, A. J. Oportunidades para 
ecodesign na embalagem, produção e distribuição de lichia a partir da Avaliação do Ciclo de Vida. In: SILVEIRA, A. L. M. da; FRANZATO, C.; LINDEN, J. van der. (Org.). Caminhos para a sustentabilidade através do design. Porto Alegre: Editora Uniritter, 2014, v. 1, p. 133-148.

PEREIRA, A. F. ACV para designers e arquitetos: experiências de modelamento do inventário do ciclo de vida. In: OLIVEIRA, A. J. de; FRANZATO, C.; DEL GAUDIO, C. (Org.). Ecovisões projetuais: pesquisas em design e sustentabilidade no Brasil. São Paulo: Blucher, 2017. p. 219-234.

PREFEITURA DO MUNICÍPIO DO SERRO. Galeria de Fotos - Cultura - 07 de Setembro 2019 em Serro, 2019. Disponível em: https://www.serro.mg.gov.br/. Acesso em: 19 fev. 2021.

QUEIROGA, V. de P. et al. Tecnologias de Plantio da Macaubeira na Região Nordeste e Aproveitamento Energético. Campina Grande: AREPB, 2016. Disponível em: https://issuu.com/abarriguda/docs/livro_macaubeira. Acesso em: 20 jan. 2021.

RIZZON, L. A. DALL'AGNOL, I. Vinho Branco. Brasília: Embrapa Informação Tecnológica, 2009. Disponível em: https://www.embrapa.br/busca-de-publicacoes/-/publicacao/662684/vinho-branco. Acesso em: 20 jan. 2021.

SANJINEZ-ARGANDOÑA, E. J. CHUBA, C. A. M. Caracterização biométrica, física e química de frutos da palmeira Bocaiúva Acrocomia aculeata (Jacq) Lodd. Revista Brasileira de Fruticultura, Jaboticabal, v. 33, n. 3, p. 1023-1028, set. 2011. Disponível em: https://www.scielo.br/scielo.php?script=sci_arttext\&pid=S0100-29452011000300040\&lng=pt\&tlng=pt. Acesso em: 20 jan. 2021.

SILVA, J.C. Macaúba: fonte de matéria-prima para os setores alimentício, energético e industrial. Viçosa: CEDAF/DEF/UFV, 1994. 44p.

SILVA, N. D. et al. Avaliação da produção agrícola da Macaúba. In: CONGRESSO BRASILEIRO DE PLANTAS OLEAGINOSAS, ÓLEOS, GORDURAS E BIODISEL, V, 2008, Lavras. Livro de resumos... Lavras: [s.n.], 2008. p. 1-10.

TECFAG. Envasadora de 2 bicos de líquidos (1001000 ml) - SYF2 1000. [S. I.], 2021. Disponível em: https://www.tecfag.com.br/envasadora-de-2-bicos-de-liquidos-100-1000-ml-syf2-1000. Acesso em: $10 \mathrm{fev}$. 2021.

\section{AUTORES}

ORCID: https://orcid.org/0000-0001-9132-4788

ADRIANA LUÍSA DUARTE | Universidade do Estado de Minas Gerais (UEMG), Design, Belo Horizonte, MG, Brasil Correspondência para: Rua Flor da Verdade, 167 - Jardim Alvorada, Belo Horizonte - MG, 30810-110 | e-mail: luisaduarte.designer@gmail.com

ORCID: https://orcid.org/0000-0001-8968-8099

ALICE NOVATO SILVA DE FARIA | Universidade do Estado de Minas Gerais (UEMG), Design, Belo Horizonte, MG, Brasil | Correspondência para: Rua Ouro Fino, 59 / apto. 401 Cruzeiro, Belo Horizonte - MG 30310-110 |e-mail: alicensfaria@gmail.com

ORCID: https://orcid.org/0000-0002-7751-2069

LUDMILA CARDOSO FAGUNDES MENDES | Universidade Federal de Minas Gerais (UFMG), Ambiente Construído e Patrimônio Sustentável, Belo Horizonte, MG, Brasil | Correspondência para: Rua Planetóides, 271 - Santa Lúcia, Belo Horizonte MG 30360-440 | e-mail: ludmilamendes@ufmg.br

ORCID: https://orcid.org/0000-0001-8810-7598

KÁTIA ANDRÉA CARVALHAES PÊGO, Dra. | Universidade do Estado de Minas Gerais (UEMG), Design, Belo Horizonte, MG, Brasil | Correspondência para: Rua Angra, 91 / apto. 501Nova Granada, Belo Horizonte - MG, 30431-305 | e-mail: katia.pego@uemg.br

ORCID: https://orcid.org/0000-0002-3633-4884

ANDRÉA FRANCO PEREIRA, Dra. | Universidade Federal de Minas Gerais (UFMG), Ambiente Construído e Patrimônio Sustentável, Belo Horizonte, MG, Brasil | Correspondência para: Rua Santa Rita Durão, 61, Apto 702 - Funcionários, Belo Horizonte - MG, 30140-110 | e-mail: andreafranco@ ufmg.br

\section{COMO CITAR ESTE ARTIGO}

DUARTE, Adriana Luisa; FARIA, Alice Novato Silva de; MENDES, Ludmila C. F.; PÊGO, Kátia Andréa Carvalhaes; PEREIRA, Andréa Franco. Na Abordagem Sistêmica E O Ciclo De Vida Do Licor De Macaúba. MIX Sustentável, [S.I.], v. 7, n. 4, p. 137-148, set. 2021. ISSN 24473073. Disponível em:<http://www.nexos.ufsc.br/index.php/ mixsustentavel>. Acesso em: dia mês. ano. doi:https:// doi.org/10.29183/2447-3073.MIX2021.v7.n4.137-148.

DATA DE ENVI0: 25/06/2021

DATA DE ACEITE: 01/07/2021 